\title{
PHOTOELECTRON SPECTROSCOPIC STUDIES ON THE DISSOCIATION OF CO ON POTASSIUM-DOSED Rh(111) SURFACE
}

\author{
János KISS, Gábor KLIVÉNYI, Károly RÉVÉSZ and Frigyes SOLYMOSI \\ Reaction Kinetics Research Group of the Hungarian Academy of Sciences and Institute of Solid State \\ and Radiochemistry, University of Szeged, P.O. Box 105, H-6701 Szeged, Hungary
}

Received 7 June 1989; accepted for publication 25 July 1989

\begin{abstract}
Adsorption of $\mathrm{CO}$ has been investigated on clean and potassium-dosed $\mathrm{Rh}(111)$ surfaces by means of TDS, UPS, XPS and work function measurements. CO adsorbs molecularly at $90-300 \mathrm{~K}$ on $\mathrm{Rh}(111)$ dosed with $\mathrm{K}$ up to a monolayer coverage. No spectroscopic evidences were found for the dissociation of $\mathrm{CO}$ in the coadsorbed layer heated to near the onset temperature of $\mathrm{CO}$ desorption. A well detectable dissociation of $\mathrm{CO}$ was observed following electron bombardment of the coadsorbed layer. The effect of potassium on the reaction of adsorbed oxygen and carbon (produced by electron bombardment or by decomposition of ethylene) was also examined. Formation of chemisorbed $\mathrm{CO}$ at $\theta_{\mathrm{K}}=0.33$ occurred at $400-500 \mathrm{~K}$, far below the desorption of $\mathrm{CO}$ from this surface. A promoting effect of potassium was established. It was concluded that $\mathrm{CO}$ desorbs from K-dosed Rh(111) without undergoing a significant dissociation, and the isotopic scrambling between labelled $\mathrm{CO}$ proceeds likely via a nondissociative mechanism.
\end{abstract}

\section{Introduction}

We recently investigated the adsorption of $\mathrm{CO}_{2}$ on the potassium-promoted $\mathrm{Rh}(111)$ surface [1,2]. Potassium dramatically influcnced the bonding and reactivity of $\mathrm{CO}_{2}$ adsorbed on $\mathrm{Rh}(111)$; it increased the binding energy, induced the formation of new adsorption states and initiated the dissociation of $\mathrm{CO}_{2}$. From the UPS and XPS data it was concluded that the activation of $\mathrm{CO}_{2}$ through formation of the $\mathrm{CO}_{2}^{-}$anion radical, which dissociates to $\mathrm{CO}$ and $\mathrm{O}$ at $131-179 \mathrm{~K}$ at low $\mathrm{K}$ coverage $\left(\theta_{\mathrm{K}} \simeq 0.1\right)$ and disproportionates into carbonate and $\mathrm{CO}$ above $238 \mathrm{~K}$ at $\theta_{\mathrm{K}}=0.3$. It remained an open question whether the $\mathrm{CO}$ formed in the above processes underwent further dissociation or retained its molecular identity until its desorption. Analysis of the data obtained did not reveal any indication of the dissociation of $\mathrm{CO}$ in the $\mathrm{CO}_{2}+\mathrm{K} / \mathrm{Rh}$ system. This might be due to the presence of absorbed oxygen, as the dissociation of $\mathrm{CO}$ has been established before on the K-promoted $\mathrm{Rh}(111)$ surface $[3,4]$.

The dissociation of $\mathrm{CO}$ on transition metal surfaces has been the subject of extensive research, as it is of strong relevance to the catalytic synthesis of 
hydrocarbons and alcohols. The unambiguous establishment of $\mathrm{CO}$ dissociation is not always very simple; several potentially disturbing factors should be excluded before a final conclusion is reached. This is well demonstrated by the controversy on the dissociation of $\mathrm{CO}$ on clean Rh surfaces [5-13]. It now appears certain that $\mathrm{CO}$ adsorbs predominantly molecularly on clean $\mathrm{Rh}$ surfaces under UHV conditions and the probability of $\mathrm{CO}$ dissociation at $370-870 \mathrm{~K}$ is negligible $[7,8]$. On supported $\mathrm{Rh}$ and at ambient pressure the dissociation of $\mathrm{CO}$ has been detected only above $473 \mathrm{~K}[12,13]$. The reactivity of other Pt metals is practically identical: no dissociation of $\mathrm{CO}$ occurs up to $300 \mathrm{~K}$ under UHV conditions [14].

The situation could obviously be different in the presence of potassium which drastically decreases the $\mathrm{C}-\mathrm{O}$ stretching frequencies and increases the binding energy of $\mathrm{CO}$ for all transition metals. Although the extents of these changes are practically the same [15], the absorbed $\mathrm{CO}$ even on potassiumdosed Pt metals exhibited different reactivities [15-30]. On $\mathrm{Rh}(111)$, it was found that potassium adatoms not only weaken the $\mathrm{C}-\mathrm{O}$ bond, but can ultimately lead to its rupture [3,4]. This was established from isotopic mixing experiments but was not confirmed by spectroscopic studies. The same conclusion was reached for $\mathrm{Fe}(100), \mathrm{Fe}(111)[16], \mathrm{Ni}(100)[17,18]$ and $\mathrm{Ni}(111)[19,20]$ surfaces, where the dissociation of $\mathrm{CO}$ was observed at $300-400 \mathrm{~K}$. On the other hand, dissociation of $\mathrm{CO}$ has not been observed or reported for the K-promoted $\mathrm{Ni}(100)$ [21], $\mathrm{Ru}(001)$ [22-24], $\mathrm{Pt}(111)$ [25-27], $\mathrm{Pd}(100)$ and $\operatorname{Pd}(110)[28-30]$ surfaces in this temperature range.

In the present study, the interaction of $\mathrm{CO}$ with $\mathrm{K}$-dosed $\mathrm{Rh}(111)$ is examined by means of TPD, $\Delta \phi$, UPS and XPS measurements, with particular attention to the dissociation of $\mathrm{CO}$.

\section{Experiments}

The experiments were carried out in an ultrahigh-vacuum chamber with a base pressure of $5 \times 10^{-10}$ Torr, equipped with a hemispherical analyzer (Leybold-Hereaus LHS-10) for UPS, XPS and AES, and a quadrupole mass spectrometer for TDS [2].

UPS were performed by using $\mathrm{HeI}(21.22 \mathrm{eV})$ and $\mathrm{He}$ II $(40.81 \mathrm{eV})$ radiation. The angles between the surface normal and the UV lamp and between the surface normal and the analyzer were $75^{\circ}$ and $16^{\circ}$, respectively. Work function measurements were obtained from He I spectra. The photoelectrons were excited by $\mathrm{Al} \mathrm{K} \alpha$ radiation $(1486.7 \mathrm{eV})$ in the XPS regime. The pass energy was $50 \mathrm{eV}$ and the resolution is estimated to be $\sim 1.2 \mathrm{eV}$. The accuracy of the determination of the position of $O(1 \mathrm{~s})$ binding energy is $\pm 0.2 \mathrm{eV}$. The experimental data were collected with a multichannel analyzer (TracorNorthem 1710) and a computer. 
High resolution, electron-induced Auger spectra were taken in $\mathrm{d} N(E) / \mathrm{d} E$ mode using a lock-in amplifier (Ithaco, Dinatrac $391 \mathrm{~A}$ ) with $0.5 \mathrm{eV}$ peak-topeak modulation, $1 \mu \mathrm{A}$ of indicident current and $2.5 \mathrm{kV}$ of incident energy. The cleaning procedure for the $\mathrm{Rh}(111)$ and crystal mount have been previously described [1].

Potassium was deposited on $\mathrm{Rh}(111)$ at room temperature by resistively heating a getter wire source (SAES getter) located $2 \mathrm{~cm}$ from the sample. The time required for potassium deposition was $0.5-2 \mathrm{~min}$. The $K$ coverage was calibrated using LEED, AES and TPD yield, and was described elsewhere [1,3]. A monolayer of potassium on $\mathrm{Rh}(111)$ corresponds to a surface density of $5.8 \times 10^{14}$ atoms $/ \mathrm{cm}^{2}$ or $\theta_{\mathrm{K}}=0.36$ potassium atom per surface rhodium atom.

\section{Results}

\subsection{Characteristics of $\mathrm{CO}+\mathrm{K}$ coadsorbed layer on $\mathrm{Rh}(111)$}

In the first part of the experiments we confirmed the characteristics of thermal desorption of $\mathrm{CO}$ from clean and K-promoted $\mathrm{Rh}(111)$ surfaces. $\mathrm{CO}$ desorbs from the K-free surface in a broad peak, with $T_{\mathrm{p}}=490 \mathrm{~K}$. The total uptake of $\mathrm{CO}$ and the amount of $\mathrm{CO}$ desorbed in this peak decrease with increase of the potassium coverage. At the same time, at above $\theta_{\mathrm{K}}=0.15 \mathrm{a}$ new high temperature state develops with $T_{\mathrm{p}}=700 \mathrm{~K}$. Above $\theta_{\mathrm{K}}=0.3$, the desorption of $\mathrm{CO}$ mainly occurs from this high-temperature state. These features show excellent agreement with those established by Somorjai et al. $[3,4]$.

Figs. 1a and $1 \mathrm{~b}$ display UPS spectra from the adsorbed layer at $300 \mathrm{~K}$ and after gradual heating to higher temperatures. We note here that the spectra obtained following $\mathrm{CO}$ adsorption on clean and $\mathrm{K}$-dosed $\mathrm{Rh}(111)$ at $100 \mathrm{~K}$ exhibited exactly the same features as at $300 \mathrm{~K}$. As observed previously [2], the deposition of potassium on $\mathrm{Rh}(111)$ decreased and broadencd the cmission of the d-band of Rh. This effect increased with the K coverage. At $\theta_{\mathrm{K}}=0.1$, the $\mathrm{K}(3 \mathrm{p})$ level appeared at $18.0 \mathrm{eV}$ in the He II UPS spectrum. At monolayer coverage, the position of this peak was observed at $17.7 \mathrm{eV}$.

Adsorption of $\mathrm{CO}$ on $\mathrm{K}$-dosed surface at $\theta_{\mathrm{K}}=0.1$ caused a shift in the $\mathrm{K}(3 \mathrm{p})$ signal to lower energy, $17.8 \mathrm{eV}$ (this is clearly seen in the difference spectrum). Additionally, two new signals were produced, at 8.0 and $10.9 \mathrm{eV}$. No changes in the positions and intensities of these signals were observed up to $420 \mathrm{~K}$. The signals were eliminated at $540-570 \mathrm{~K}$ without any indication of the development of a new emission.

At near monolayer $\mathrm{K}$ coverage $\left(\theta_{\mathrm{K}}=0.33\right)$, the coadsorbed $\mathrm{CO}$ enhanced the intensity of the emission of $\mathrm{K}(3 \mathrm{p})$. New photoemission signals appeared at 

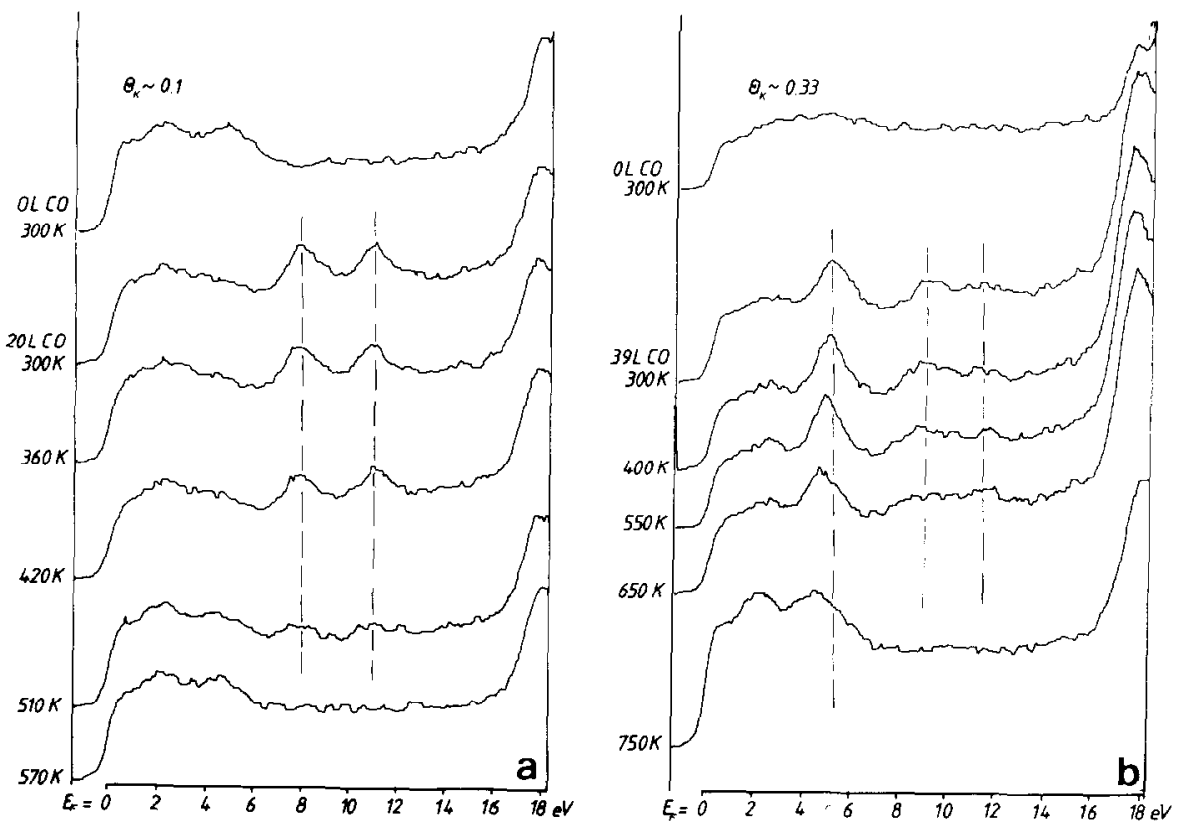

Fig. 1. He II photoelectron spectra of adsorbed CO on K-dosed Rh(111) at different temperatures. (a) $\theta_{\mathrm{K}}=0.1$; (b) $\theta_{\mathrm{K}}=0.33$.

5.2, 9.0 and $11.5 \mathrm{eV}$. Upon heating of the adsorbed layer, the intensities of all the peaks gradually decreased above $550 \mathrm{~K}$. They were eliminated between 700 and $750 \mathrm{~K}$. No new emission were detected during this heat treatment. The remaining spectrum corresponds well to that of a clean $\mathrm{Rh}(111)$ pertubed by a small amount of potassium.

For comparison, similar studies were performed with a clean surface. The adsorption of $\mathrm{CO}$ in this case produced new signals at lower binding energies, 7.9 and $10.8 \mathrm{cV}$. Attenuation of these peaks occurred above $400 \mathrm{~K}$; they were completely eliminated at $500 \mathrm{~K}$, without producing any additional spectral features.

In another series of experiments, the coadsorbed layer of $\mathrm{CO}$ and $\mathrm{K}$ was kept at the high temperature of $604 \mathrm{~K}$, just below the desorption of $\mathrm{CO}$, and the UPS spectrum was registered at certain times up to $30 \mathrm{~min}$. The difference spectra taken at 300 and $600 \mathrm{~K}$ showed no new peaks which could be attributed to adsorbed oxygen and carbon.

These measurements have been repeated by means of XPS. Following potassium adsorption, two signals were detected at 293.3 and $295.4 \mathrm{eV}$, which are due to spin-orbit splitting of the $\mathrm{K}(2 \mathrm{p})$ level into $2 \mathrm{p}_{3 / 2}$ and $2 \mathrm{p}_{1 / 2}$ components [2]. 

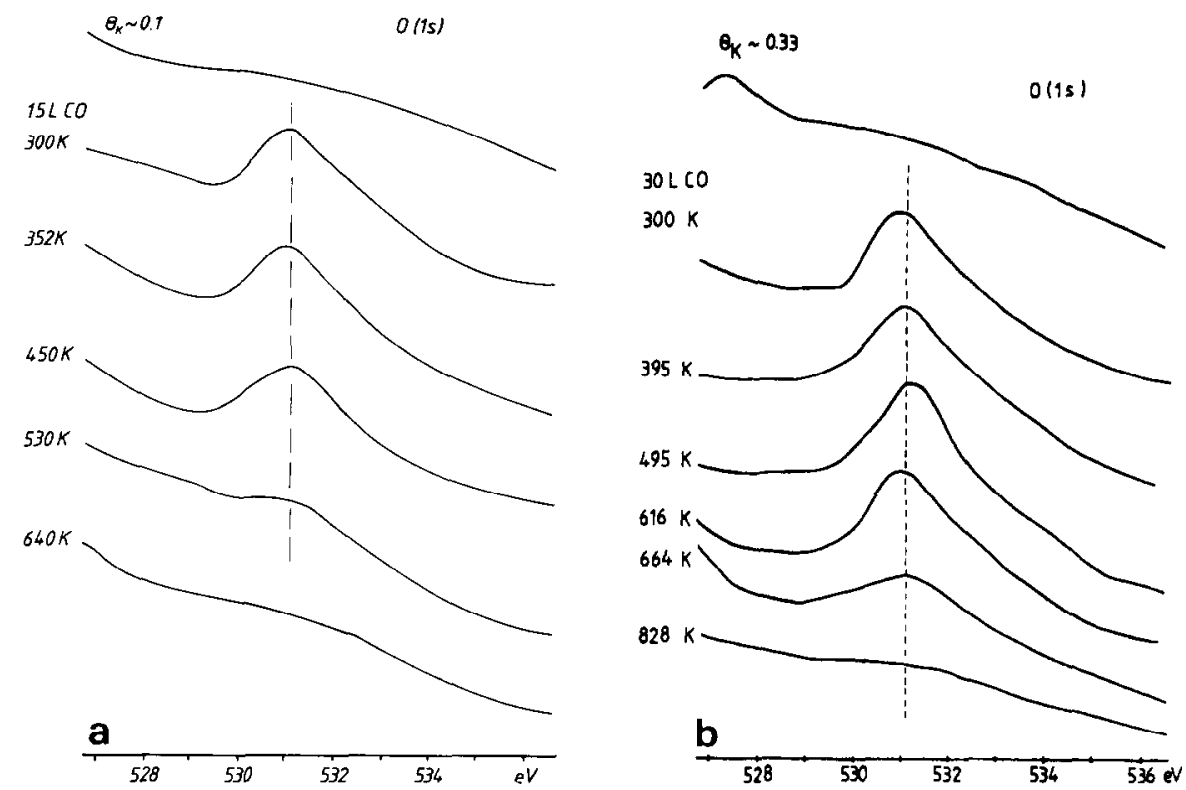

Fig. 2. X-ray photoelectron spectra of adsorbed $\mathrm{CO}$ on $\mathrm{K}$-dosed $\mathrm{Rh}(111)$ at different temperatures. (a) $\theta_{\mathrm{K}}=0.1 ;$ (b) $\theta_{\mathrm{K}}=0.33$.

The adsorption of $\mathrm{CO}$ on the clean $\mathrm{Rh}(111)$ surface produced two peaks in the XPS spectrum, at $531.4 \mathrm{eV}$ for $\mathrm{O}(1 \mathrm{~s})$ and $285.6 \mathrm{eV}$ for $\mathrm{C}(1 \mathrm{~s})$. In harmony with the results of UPS studies, the peaks for the clean surface decreased in intensity when the coadsorbed layer was heated above $400 \mathrm{~K}$, and they vanished at about $500 \mathrm{~K}$.

The adsorption of $\mathrm{CO}$ on potassium-dosed $\mathrm{Rh}(111)$ shifted the potassium signals to lower binding energy. The $O(1 \mathrm{~s})$ and $C(1 \mathrm{~s})$ levels appeared at same energies as for a clean surface. These peaks disappeared at $550 \mathrm{~K}$ for $\theta_{\mathrm{K}}=0.1$ (fig. 2a) and above $720 \mathrm{~K}$ for $\theta_{\mathrm{K}}=0.33$ (fig. 2b), without any significant shift to lower binding encrgy. When the coadsorbed layer at $\theta_{K}=0.33$ was heated to $604 \mathrm{~K}$ near the temperature of onset of $\mathrm{CO}$ desorption for $10 \mathrm{~min}$ and then cooled back $300 \mathrm{~K}$, there was no significant alteration relative to the XPS spectrum registered previously at $300 \mathrm{~K}$ (fig. 3). The subtraction of the clean surface sloping background gave no low energy shoulder neither for the results presented in fig. $2 \mathrm{~b}$ nor fig. 3 . The adsorption of oxygen on this surface $\left(\theta_{\mathrm{K}}=0.33\right)$ produces an $\mathrm{O}(1 \mathrm{~s})$ peak at $530.0 \mathrm{eV}$ (fig. 3).

Work function changes observed for Rh samples following the adsorption of $\mathrm{CO}$ and after subsequent heating can be seen in fig. 4. It may be mentioned that the work function of $\mathrm{Rh}(111)$ decreased linearly with $\mathrm{K}$ exposure up to $\theta_{\mathrm{K}}=0.17$, with $\Delta \phi=-3.5 \mathrm{eV}$ [1]. Further $\mathrm{K}$ deposition led to a slight increase $(0.5 \mathrm{eV})$. The adsorption of $\mathrm{CO}$ at $300 \mathrm{~K}$ caused an increase in the work 


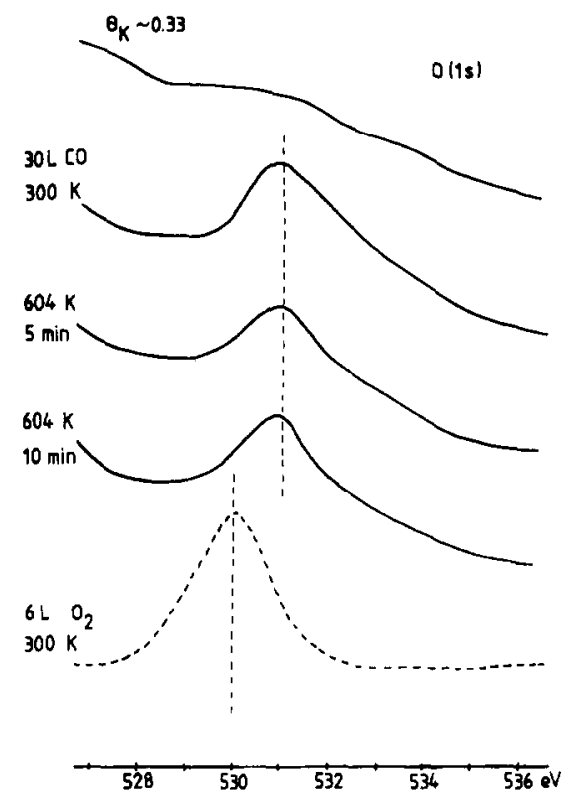

Fig. 3. Effect of annealing the adsorbed layer at $604 \mathrm{~K}$ on the X-ray photoelectron spectra. Adsorption temperature of $\mathrm{CO}$ was $300 \mathrm{~K}$. The spectrum of $\mathrm{O}(1 \mathrm{~s})$ level after adsorption of oxygen is also shown. $\theta_{\mathrm{K}}=0.33$.

function of all samples. Upon heating of the adsorbed layer, the work function started to decrease at $350 \mathrm{~K}$ for the clean $\mathrm{Rh}$. This decrease was sharp and continuous, and the original value was attained at $600 \mathrm{~K}$. In the case of an K-promoted surface, the situation was more complex. The work function

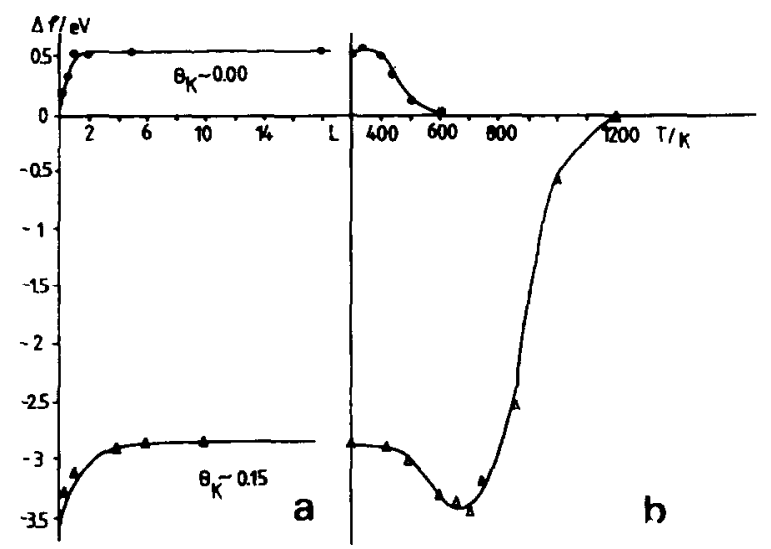

Fig. 4. Changes in the work function of clean and K-dosed Rh(111) following CO adsorption at $100 \mathrm{~K}$ (a) and after heating the coadsorbed layer to different temperatures (b). 
decreased between 420 and $700\left(\theta_{\mathrm{K}}=0.15-0.20\right)$, where $\mathrm{CO}$ desorption occurs. This was followed by a continuous increase in $\Delta \phi$ from 700 to $1200 \mathrm{~K}$, which may correspond to the desorption of potassium.

\subsection{Electron beam-induced reactions in the $C O+K / R h(111)$ system}

The effects of electron beam bombardment on the thermal desorption of $\mathrm{CO}$ from clean and potassium-dosed surfaces are shown in fig. 5. The fraction of the crystal surface irradiated by the electron beam was about $2 \mathrm{~mm}^{2}$. The back face was not irradiated. For the clean surface, the area of the single desorption peak was reduced by $20 \%$ and an additional broad peak appeared at around $700 \mathrm{~K}$ after clectron bombardment $(2 \mu \mathrm{A}, 10 \mathrm{~min})$. The area of the new peak was less than $1 \%$ of that of the main peak at this electron exposure. When the electron-bombarded surface covered by $\mathrm{CO}$ was heated to $600 \mathrm{~K}$ (above the desorption temperature of $\mathrm{CO}$ ), traces of adsorbed oxygen and carbon were detected by AES; they disappeared completely at $800 \mathrm{~K}$. The high-temperature $\mathrm{CO}$ desorption peak is attributed to the recombination of chemisorbed carbon and oxygen atoms, caused by impinging electrons. Electron-induced dissociation of adsorbed $\mathrm{CO}$ was also found on this surface in an early publication [8]. We note that according to the TPD data the electron

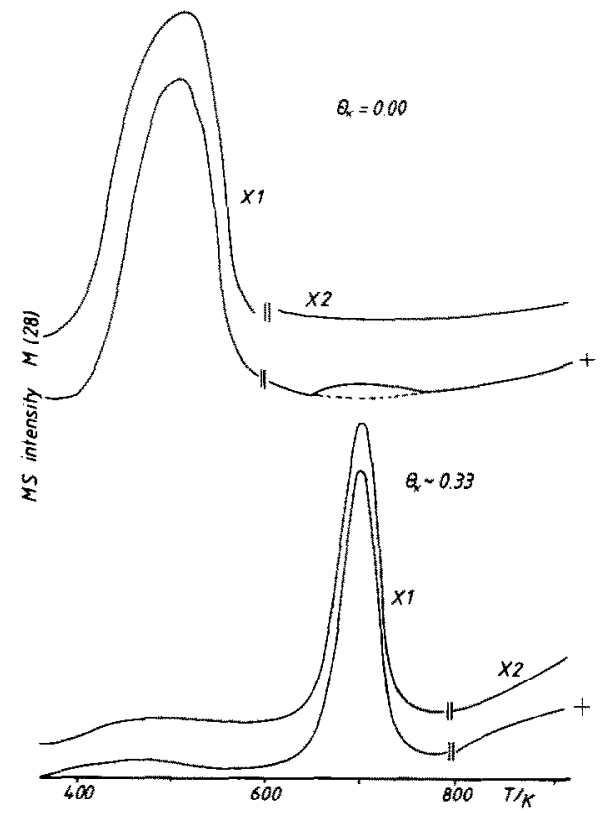

Fig. 5. Effects of electron-bombardment of adsorbed layer on the thermal desorption of CO from clean and $\mathrm{K}$-dosed $\theta_{\mathrm{K}}=0.33 \mathrm{Rh}(111)$ surfaces. Curves marked with "+ " are with electron bombardment. 


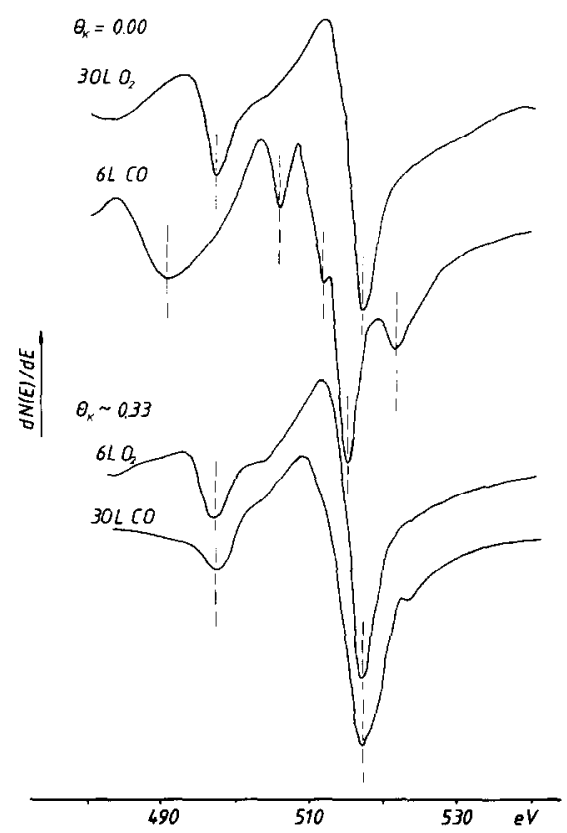

Fig. 6. Effects of electron bombardment on the electron-excited Auger fine structure of the adsorbed $\mathrm{CO}$ on clean and $\mathrm{K}$-dosed $\left(\theta_{\mathrm{K}}=0.33\right) \mathrm{Rh}(111)$ surfaces at $300 \mathrm{~K}$. Beam current was 2 $\mu \mathrm{A}$, exposure time $10 \mathrm{~min}$. AES spectra following oxygen adsorption are also shown.

beam-induced desorption of $\mathrm{CO}$ was more than twenty times faster than the dissociation. The same feature has been observed on $\operatorname{Pt}(111)$ [31].

Similar experiments were performed on the potassium-dosed surface $\left(\theta_{\mathrm{K}}=\right.$ $0.33)$. Surprisingly, the electron bombardment did not cause any observable change in the position and quantity of the $\mathrm{CO}$ desorption (fig. 5). The beam-induced desorption was negligible in contrast with that on the clean surface.

Fig. 6 displays the electron-excited AES fine structures of $\mathrm{O}(\mathrm{KVV})$ for adsorbed $\mathrm{CO}$ obtained on clean and $\mathrm{K}$-dosed $\left(\theta_{\mathrm{K}}=0.33\right)$ surfaces at $300 \mathrm{~K}$ in the first derivative mode. For comparison, this figure also shows the AES fine structures of $O(K L L)$ after oxygen adsorption on both surfaces. In these experiments, the beam exposures were the same as those used in the TDS measurements. On the clean surface, the same five-peaks structure was measured, with almost identical kinetic energies for the CO-covered surface as found in the $\mathrm{CO} / \mathrm{Ru}(001)$ system using $\mathrm{X}$-ray-induced AES at a polar angle of $\theta=0^{\circ}[32]$. This structure is basically different from that of $\mathrm{O}(\mathrm{KLL})$ obtained after oxygen adsorption on $\mathrm{Rh}(111)$ (fig. 6), indicating that the majority of adsorbed $\mathrm{CO}$ preserved its molecular identity on the clean surface after electron bombardment. The situation was completely different for the K-dosed 
$\mathrm{Rh}(111)$. In this case, the AES fine structure of $\mathrm{O}(\mathrm{KLL})$ following electron bombardment of the $\mathrm{CO}+\mathrm{K}$ adlayer was practically identical with that obtained after oxygen adsorption (fig. 6). This suggests that the electron beam induced the dissociation of $\mathrm{CO}$ in the presence of preadsorbed potassium.

Similar conclusion can be drawn from XPS measurements at $\theta_{\mathrm{K}}=0.33$. Selected spectra are displayed in fig. 7. A significant broadening of the $O(1 \mathrm{~s})$ signal to lower binding energy was observed when the $\mathrm{CO}$-covered surface was exposed to an electron beam ( $2 \mu \mathrm{A}, 10 \mathrm{~min})$, indicating the formation of some surface oxygen.

\subsection{Effects of potassium on the recombination of adsorbed $O$ and $C$ on $R h(111)$}

Potassium adatoms exerted a significant promoting influence on the recombination of adsorbed $\mathrm{O}$ and $\mathrm{C}$ produced by electron bombardment at $300 \mathrm{~K}$. This is demonstrated by an experiment in which the coadsorbed layer (after electron exposure) has been heated to $450 \mathrm{~K}$. The $\mathrm{O}(1 \mathrm{~s})$ peak shifted back to $531.2 \mathrm{eV}$, and remained constant in position and intensity even at $600 \mathrm{~K}$ (fig. 7). Above $750 \mathrm{~K}$, there was no signal, neither for adsorbed oxygen nor for $\mathrm{CO}$ on this surface.

The recombination process between adsorbed oxygen and surface carbon was studied on the clean and $\mathrm{K}$-dosed $\mathrm{Rh}$ surface in a greater detail. The carbon deposit was produced by exposing the surface to $\mathrm{C}_{2} \mathrm{H}_{4}$ at $300 \mathrm{~K}$, and

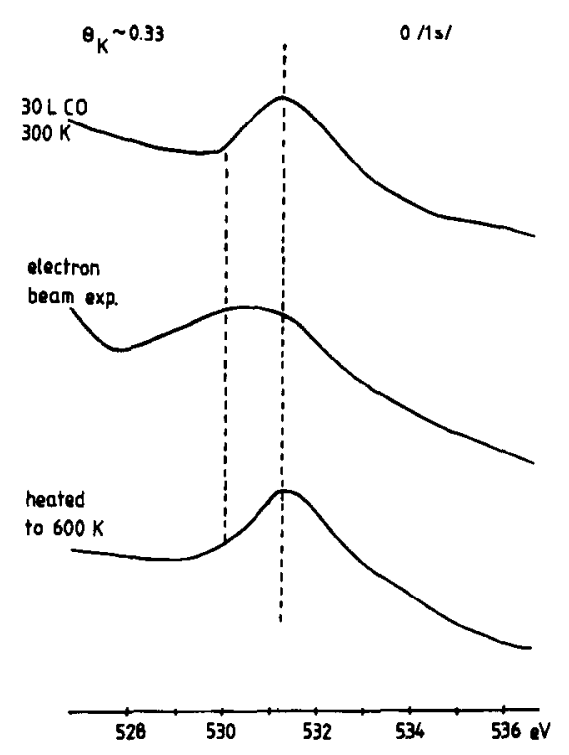

Fig. 7. X-ray photoelectron spectra of adsorbed CO on K-dosed $\left(\theta_{K}=0.33\right) \operatorname{Rh}(111)$ following electron-bombardment at $300 \mathrm{~K}$ and subsequent heating to $600 \mathrm{~K}$. 


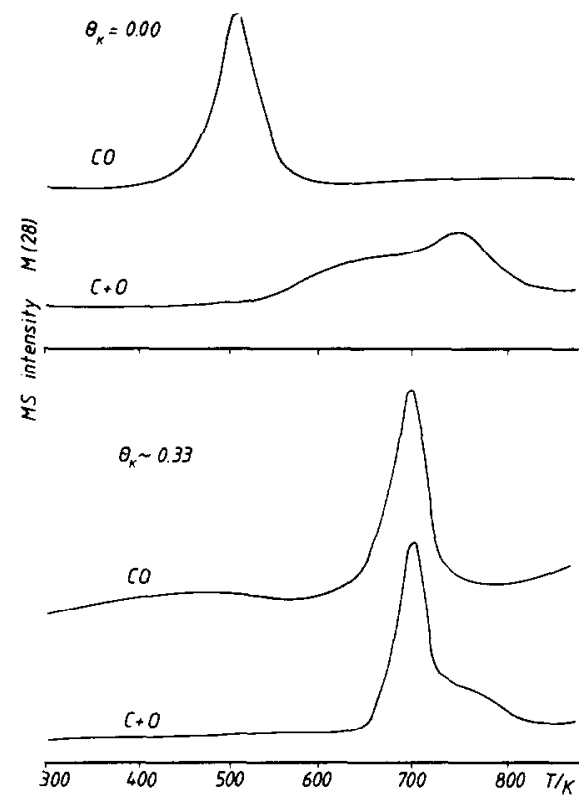

Fig. 8. Thermal desorption spectra for $\mathrm{CO}$ formed in the surface reaction of adsorbed $\mathrm{C}$ (produced by decomposition of $\mathrm{C}_{2} \mathrm{H}_{4}$ ) and $\mathrm{O}$ on clean and $\mathrm{K}$-dosed $\mathrm{Rh}(111)$. The $\mathrm{CO}$ desorption curve after adsorption of $\mathrm{CO}\left(4 \times 10^{14}\right.$ molecules $\left./ \mathrm{cm}^{2}\right)$ are also shown in both surfaces.

flashing the sample to $800 \mathrm{~K}$ [33]. After cooling to room temperature, the $\mathrm{C}$-covered surface was exposed to oxygen. For study of the effect of potassium, the $\mathrm{C}+\mathrm{O}$-covered surface was exposed to potassium at $300 \mathrm{~K}$. The relative amounts of surface carbon and oxygen were adjusted so as to obtain an oxygen to carbon ratio for an AES signal characteristic of $\mathrm{CO}$ adsorption. The concentration of $C$ and $O$ on $R h$ surface were the same $\left((4-5) \times 10^{14}\right.$ molecules $/ \mathrm{cm}^{2}$ ) in all cases.

On the clean surface, the adsorbed carbon and oxygen produced $\mathrm{CO}$ desorption with peak maxima at 660 and $750 \mathrm{~K}$ (fig. 8). These desorption states appeared at higher temperatures than after $\mathrm{CO}$ adsorption on this surface. On the K-dosed sample, the characteristics of $\mathrm{CO}$ desorption due to the recombination of carbon and oxygen were the same as after $\mathrm{CO}$ adsorption on this surface $\left(T_{\mathrm{p}}=700 \mathrm{~K}\right)$; only a shoulder appeared with $T_{\mathrm{p}}=750 \mathrm{~K}$, which can be seen on the clean surface, too (fig. 8). The amount of $\mathrm{CO}$ formed in the high temperature stage is about $21 \%$ of that desorbed in the peak with $T_{\mathrm{p}}=700 \mathrm{~K}$. Taking into account the characteristics of $\mathrm{CO}$ desorption from $\mathrm{K}$-dosed $\mathrm{Rh}$ we conclude that the high temperature $\mathrm{CO}$ peak represents reaction (recombination) rate limited $\mathrm{CO}$ desorption. With the increase of the surface concentrations of adsorbed $\mathrm{C}$ and $\mathrm{O}$ on this surface, only the peak with $T_{\mathrm{p}}=700 \mathrm{~K}$ increased further. 

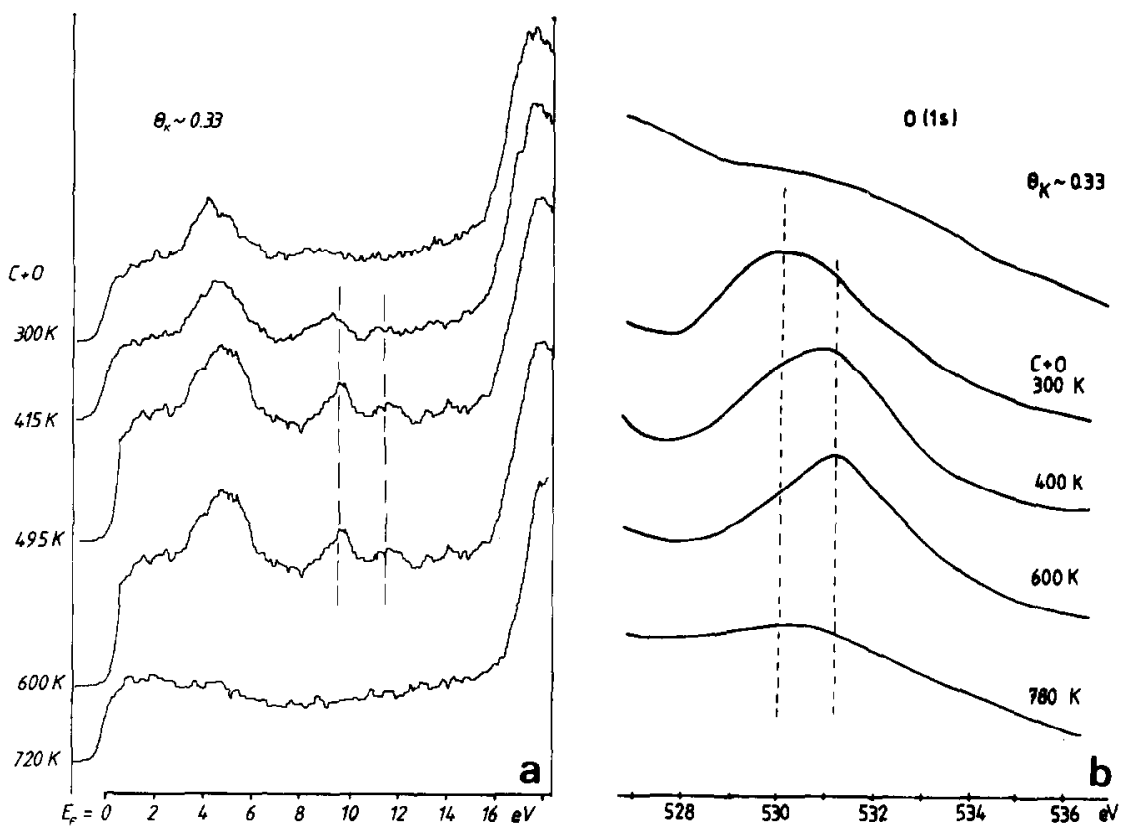

Fig. 9. Photoelectron spectra of coadsorbed $C$ (produced by $\mathrm{C}_{2} \mathrm{H}_{4}$ decomposition) and $\mathrm{O}$ and $\mathrm{K}$-dosed $\left(\theta_{\mathrm{K}}=0.33\right) \mathrm{Rh}(111)$ at $300 \mathrm{~K}$ and after heating to higher temperatures. (a) UPS; (b) XPS for $O(1 s)$ level.

Fig. 9a shows the UPS spectra of the $\mathrm{C}+\mathrm{O}$ coadsorbed system at different temperatures at $\theta_{\mathrm{K}}=0.33$. Initially, the spectrum registered at $300 \mathrm{~K}$ exhibited broad features at $4-6 \mathrm{eV}$ which correspond to the adsorbed $\mathrm{C}$ and $\mathrm{O}$. When the surface was heated to $400 \mathrm{~K}$, this feature was partially replaced by the 5.2 $\mathrm{eV}$ peak and two new peaks appeared at 9.4 and $11.5 \mathrm{eV}$, slightly different energies as after $\mathrm{CO}$ adsorption on this surface. A small increase in their intensities was observed up to $495 \mathrm{~K}$. The new photoemission peaks vanished between 600 and $720 \mathrm{~K}$.

Drastic changes were detected in the XPS, too (fig. 9b). The K-dosed surface on which $\mathrm{C}$ and $\mathrm{O}$ were deposited produced a peak at $530.0 \mathrm{eV}$ for $\mathrm{O}(1 \mathrm{~s})$ at $300 \mathrm{~K}$. At $400 \mathrm{~K}$, the peak shifted to $531.2 \mathrm{eV}$ : a small shoulder remained at $530.0 \mathrm{eV}$. At $600 \mathrm{~K}$, mainly the peak at $531.2 \mathrm{eV}$ was observed, indicating that the atomic oxygen reacted with carbon to produce adsorbed CO below the desorption temperature.

\section{Discussion}

\subsection{Characteristics of adsorbed $C O$ on $K+R h(111)$ surface}

Although the primary aim of this work was to find spectroscopic evidence for or against the dissociation of CO on K-dosed $\mathrm{Rh}(111)$, we may deal briefly 
with other properties of the $\mathrm{CO}+\mathrm{K}$ coadsorbed layer on the $\mathrm{Rh}$ surface. According to previous studies [3,4], the coadsorbed layer over Rh(111) exhibits the same characteristics as other transition metals [34]: a drastic increase in the binding energy of $\mathrm{CO}$, a coincident thermal desorption of $\mathrm{CO}$ and $\mathrm{K}$ at higher $\mathrm{K}$ coverages, a marked decrease in the $\mathrm{CO}$ stretching frequency, and a weakening of the $\mathrm{C}-\mathrm{O}$ bond.

The present photoelectron and $\Delta \phi$ measurements provided additional evidence for the strong interaction between $\mathrm{CO}$ and $\mathrm{K} / \mathrm{Rh}(111)$. On a clean surface, the $\mathrm{CO}$ adsorption at $300 \mathrm{~K}$ produced peaks at $7.9 \mathrm{eV}$ and $10.8 \mathrm{eV}$ in UPS, and $285.6 \mathrm{eV} \mathrm{C}(1 \mathrm{~s})$ and $531.4 \mathrm{eV} \mathrm{O}(1 \mathrm{~s})$ in XPS spectrum, which are in good agreement with data determined before on the $\mathrm{Rh}(100)$ surface [35]. The peak at $10.8 \mathrm{eV}$ is assigned as emission from the $4 \sigma$ level of $\mathrm{CO}$ and the peak at $7.9 \mathrm{eV}$ is attributed to emission from unresolved $1 \pi$ and $5 \sigma$ states. On potassium-dosed $R h(111)$, the position of the $4 \sigma$ level appeared at somewhat higher binding energy $\left(10.9 \mathrm{eV}\right.$ at $\theta_{\mathrm{K}}=0.10$ and $11.2 \mathrm{eV}$ at $\left.\theta_{\mathrm{K}}=0.17\right)$. The $\mathrm{O}(1 \mathrm{~s})$ level in XPS shifted to lower energy by $0.2 \mathrm{eV}$. Similar trends were observed for the $\mathrm{CO}+\mathrm{K} / \mathrm{Pt}(111)$ system, which was correlated with an enhanced back donation of electrons into the $\mathrm{CO} 2 \pi^{*}$ orbital [27]. The work function increase found at that $\mathrm{K}$ coverage (fig. 4) is consistent with this picture.

A more significant shift occurred in the position of $\mathrm{CO}$-induced emissions in the He II photoelectron spectrum around monolayer $\mathrm{K}$ coverage. In addition, a new emission was produced at $5.2 \mathrm{eV}$. It is important to point out that this peak also appeared when $\mathrm{CO}$ was adsorbed at $100 \mathrm{~K}$ on an $\mathrm{K}$-dosed surface. Its intensity changed parallel with that of $1 \pi / 5 \sigma$ and $4 \sigma$ orbitals upon heat treatment. This peak was also detected after $\mathrm{CO}$ adsorption on $\mathrm{Fe}(110)$ [16a] and $\mathrm{Ni}(100)$ [17], and was attributed to the $2 \mathrm{p}$ emission of atomic oxygen formed in the $\mathrm{CO}$ dissociation. In these cases an intense peak developed at $5.4-6 \mathrm{eV}$ when the coadsorbed layer was heated to $390-500 \mathrm{~K}$, and the emissions of orbitals of $\mathrm{CO}$ disappeared.

The peak at $5.2 \mathrm{eV}$ also occurred in the He II spectrum following adsorption of $\mathrm{CO}, \mathrm{CO}_{2}$ and even $\mathrm{Ar}$ on $\mathrm{Ag}(111)$ where the formation of adsorbed $\mathrm{O}$ was ruled out [36]. Prince and Bradshaw [36] proposed that this peak arises from umklapp-type processes, where the photoelectrons emitted off normal are scattered into the normal direction. The peak disappeared at angles of more than $25^{\circ}$ off normal [36].

A low binding energy peak was also seen for $\mathrm{CO}$ adsorbed on the $\mathrm{K} / \mathrm{Ru}(001)$ surface $[23,37,38]$, where the dissociation of $\mathrm{CO}$ was excluded. It was interpreted by $\mathrm{sp}^{2}$ rehybridized model having new bond $\left(\mathrm{b}_{1}, \mathrm{~b}_{2}\right)$ [23,37]. Another explanation was given by Heskett et al. [38], who attributed this peak to a direct interaction between the $1 \pi$ orbitals of $\mathrm{CO}$ and potassium.

The occurrence of direct interaction at $\theta_{\mathrm{K}}=0.33$ is very likely reflected by a $0.4 \mathrm{eV}$ shift of the $\mathrm{K}(3 \mathrm{p})$ level to lower binding energy and by its significant 
intensity increase following $\mathrm{CO}$ adsorption (fig. 1b). This feature was also observed for several K-dosed metals and was associated with a direct interaction between $\mathrm{CO}$ and potassium $[38,39]$.

In previous works Crowell and coworkers $[3,4]$ interpreted the effect of potassium for the $\mathrm{CO}-\mathrm{Rh}(111)$ system as a long range electronic effect, i.e., by an enhanced backdonation of electrons from Rh into the $2 \pi$ orbital of $\mathrm{CO}$. This mechanism very likely operates at low potassium coverages, up to $\theta_{\mathrm{K}}=0.10-0.15$, where potassium exhibits mainly ionic character. This was demonstrated in our detailed study on the $\mathrm{CO}+\mathrm{K} / \mathrm{Pd}(100)$ system [30]. At high potassium coverages, where potassium exhibits mainly metallic character, there is increasing evidence for a direct chemical and/or electronic interaction between adsorbates and potassium. Formation of potassium methoxide and formate [40-42], potassium chloride [43], and potassium carbonate $[1,2,44-46]$ were spectroscopically detected. In the case of the $\mathrm{CO}+\mathrm{K} / \mathrm{M}$ system $(\mathrm{M}=$ $\mathrm{Cu}(110)$ and $\mathrm{Pd}(110))$ King and coworkers [29,47] postulated the formation of a three-dimensional oxocarbon salt " $\mathrm{K}_{2} \mathrm{C}_{2} \mathrm{O}_{2}$ " or " $\mathrm{K}_{2} \mathrm{C}_{4} \mathrm{O}_{4}$ " and concluded that the bulk of the data obtained are consistent with a salt formation model.

One piece of evidence for this model is the coincident thermal desorption traces of $\mathrm{CO}$ and $\mathrm{K}$. On the $\mathrm{Rh}(111)$ surface, this coincident temperature is $700 \mathrm{~K}$. However, as was pointed out in our previous work [15], the coincident peak temperature varies considerably with the nature of the metal; the difference between the highest and lowest value is $225 \mathrm{~K}$. The highest value was registered for $\mathrm{CO}+\mathrm{K} / \mathrm{Rh}(111)$ which - according to the salt formation model - would mean a dramatic stabilization of potassium oxocarbon compound on $\mathrm{Rh}(111)$ compared to that on $\mathrm{Cu}(110)$, which is very unlikely. Therefore we suggest that in the direct interaction between $\mathrm{K}$ and $\mathrm{CO}$, only $\mathrm{K}^{\delta+} \mathrm{CO}^{\delta-}$ surface complex is formed. As there is no, or very limited, interaction between the potassium multilayer and CO under UHV conditions, we have to assume that the above process occurs between chemisorbed $\mathrm{CO}$ and adjacent $\mathrm{K}$ on the metal surface. As a result of this interaction the binding energy of the $\mathrm{CO}$ is increased and, at the same time, the potassium is stabilized. Duc to the mutual stabilization, the $\mathrm{CO}$ and $\mathrm{K}$ desorb in the same temperature range, characterized by an identical peak temperature. A central point of this idea is that the bonding of $\mathrm{CO}$ with the host metal is preserved, and hence the stability of this surface complex is primarily determined by the strength of this bonding. Accordingly, the variation of the coincident peak temperature with the metal simply reflects the variation in strength of $\mathrm{CO}$-metal bonds which may be perturbed by potassium.

The activation of $\mathrm{CO}$ by the host metal is a primary requirement for the $\mathrm{CO}-\mathrm{K}$ interaction. In harmony with this, no adsorption of $\mathrm{CO}$ was observed on either $\mathrm{K}$-dosed $\mathrm{CaF}_{2}$ [48] or $\mathrm{Ag}(111)[49,50]$ surfaces, where the heat of $\mathrm{CO}$ adsorption on K-free host compounds is less than $5 \mathrm{kcal} / \mathrm{mol}$. 


\subsection{Dissociation of $\mathrm{CO}$}

The dissociation of $\mathrm{CO}$ on metal surfaces is a crucial point in the understanding the nature of $\mathrm{CO}$ adsorption, and this was a central issue of our work.

The isotopic mixing reaction between labelled $\mathrm{CO}$,

${ }^{12} \mathrm{C}^{18} \mathrm{O}+{ }^{13} \mathrm{C}^{16} \mathrm{O} \rightleftharpoons{ }^{12} \mathrm{C}^{16} \mathrm{O}+{ }^{13} \mathrm{C}^{18} \mathrm{O}$,

which can occur as a back reaction in the $\mathrm{CO}$ dissociation

$\mathrm{CO}_{\mathrm{a}} \rightleftharpoons \mathrm{C}_{\mathrm{a}}+\mathrm{O}_{\mathrm{a}}$,

has been extensively used to establish the dissociation of $\mathrm{CO}$ on metal surfaces. However, some care should be exercised in evaluating the data, as there is growing evidence suggesting that $\mathrm{CO}$ isotopic mixing could also proceed via a nondissociative mechanism.

Bossi et al. [51] found an exchange reaction between labelled $\mathrm{CO}$ on $\mathrm{Ru} / \mathrm{Al}_{2} \mathrm{O}_{3}$ but concluded that the isotopic mixing occurred in an intermolecular exchange reaction in the following surface complex<smiles>[R16][14C]1O[14C]([18C]=C=O)O1</smiles>

Panayotov et al. [52] also observed isotopic mixing reaction on $\mathrm{Rh} / \mathrm{Al}_{2} \mathrm{O}_{3}$ at $373-468 \mathrm{~K}$. Taking into account the other features of the interaction of $\mathrm{CO}$ with supported $\mathrm{Rh}$, they demonstrated that isotopic mixing proceeded by a nondissociative mechanism.

This isotopic exchange reaction of $\mathrm{CO}$ was also noted on $\mathrm{Cu} / \mathrm{Al}_{2} \mathrm{O}_{3}$ at 293 $\mathrm{K}$ [53], where a mechanism involving $\mathrm{CO}$ dissociation can be completely ruled out, since $\mathrm{CO}$ adsorbs only weakly on $\mathrm{Cu}$ surfaces.

A nondissociative mechanism was proposed for the exchange reaction of $\mathrm{CO}$ isotopes on potassium-dosed $\mathrm{Ni}(111)$ surface by Metiu et al. [20,54]. Although a large fraction of the $\mathrm{CO}$ was isotopically exchanged, the metastable quenching spectrum of the coadsorbed layer heated to $620 \mathrm{~K}$ (near the peak temperature of desorption) showed no evidence for the formation of adsorbed carbon and oxygen. It was suggested that the exchange reaction occurs in a coplanar four center $\mathrm{K}-\mathrm{CO}$ surface complex<smiles></smiles>

and does not involve a large fraction of dissociated $\mathrm{CO}$.

Although EELS spectroscopy showed an anomalously weakened $\mathrm{C}-\mathrm{O}$ bond on K-promoted Ru(001), TDS and EELS data provided no evidence for 
irreversible $\mathrm{CO}$ dissociation up to $500 \mathrm{~K}$ [22]. Nevertheless, a complete isotopic scrambling between ${ }^{12} \mathrm{C}^{16} \mathrm{O}$ was observed at $\theta_{\mathrm{K}}=0.1$, which led the authors to conclude that $\mathrm{CO}$ has dissociated and recombines prior to reaching the desorption temperature $(\sim 570 \mathrm{~K})$. These features could, in principle, be explained by the above nondissociative mechanisms. However, recent work by Matsushima [55], which also included the study of the exchange reactions between ${ }^{12} \mathrm{C}$ and ${ }^{13} \mathrm{C}^{18} \mathrm{O}$ and between ${ }^{18} \mathrm{O}$ and ${ }^{12} \mathrm{C}^{16} \mathrm{O}$, seems to indicate that the isotopic scrambling between $\mathrm{CO}$ molecules on $\mathrm{K}$-dosed $\mathrm{Ru}(001)$ is the result of dissociation and recombination processes.

Returning to the $\mathrm{CO}+\mathrm{KRh}(111)$ system, Crowell et al. [4] also used the method of isotopic mixing in their study. From the analysis of their isotopic exchange data, they inferred that the dissociation was near zero until $\theta_{\mathrm{K}}=0.05$ but practically all the $\mathrm{CO}$ has dissociated for $\mathrm{K}$ coverages of $\theta_{\mathrm{K}}=0.15$. The high temperature maximum for desorption of $\mathrm{CO}$ and $\mathrm{K}$ at $700 \mathrm{~K}$ was attributed to the associative desorption of $\mathrm{C}$ and $\mathrm{O}$. Note that vibrational spectroscopic data did not indicate whether $\mathrm{CO}$ bond cleavage occurred, since no significant $\mathrm{M}-\mathrm{O}$ and $\mathrm{M}-\mathrm{C}$ vibrations were detected. Nevertheless, the dissociation of $\mathrm{CO}$ can occur at higher temperature, as it is very likely that all vibrational measurements in ref. [4] were performed at room temperature or below.

However, the present XPS and UPS studies, extended to high temperatures, provided no evidence for the dissociation of $\mathrm{CO}$ even at elevated temperatures (figs. 1-3). Photoemission peaks were the same following $\mathrm{CO}$ adsorption at 100 and $300 \mathrm{~K}$, and no new signals or shifts, indicative of CO dissociation, were produced after heating the coadsorbed layer to the desorption temperature $(604 \mathrm{~K})$, or holding there for 10-20 min. Accordingly, the dissociation of $\mathrm{CO}$ on K-dosed dosed surface at $300-604 \mathrm{~K}$ is very limited, if it occurs at all, and certainly much less than inferred from isotopic exchange studies, where the extent of CO dissociation was calculated to be over $80 \%$ under optimum conditions [4]. However, this result still does not rule out the possibility that the $\mathrm{CO}$ dissociates on $\mathrm{K}$-dosed surfaces just before the $\mathrm{CO}$ desorption or, as was suggested by Crowell et al. [4], all the processes (i.e. dissociation, scrambling, recombination and desorption) proceed as a concerted process. To discuss this point further, we refer first to the results obtained following electron bombardment.

It was demonstrated that electron bombardment induces the dissociation of $\mathrm{CO}$ on both clean and $\mathrm{K}$-dosed surfaces. On clean $\mathrm{Rh}$, the associative desorption of $\mathrm{CO}$ occurred at higher temperature than the desorption of molecularly bonded $\mathrm{CO}$ (fig. 5). On the K-dosed surface, the extent of $\mathrm{CO}$ dissociation was considerably larger, which is in harmony with the previous assumption that the $\mathrm{C}-\mathrm{O}$ bond is significantly weakened by potassium. The occurrence of this process was easily detected by high resolution AES, XPS and UPS measurements. The surprising result was that on K-dosed Rh(111), 
the surface $C$ and $O$ recombined to adsorbed $\mathrm{CO}$ at $400-500 \mathrm{~K}$, far below the desorption temperature of $\mathrm{CO}$ from the K-dosed sample (figs. 6 and 7). As a consequence of this, no new TPD peak was produced in the TPD spectrum.

This feature was observed in a separate study when the surface carbon was generated by the decomposition of ethylene (figs. 8 and 9). The recombination of $\mathrm{C}$ and $\mathrm{O}$ was significantly promoted by potassium adatoms; $\mathrm{CO}$ signals in UPS and XPS appeared even above $400 \mathrm{~K}$, and CO desorbed in the same temperature range as following $\mathrm{CO}$ adsorption on the same $\mathrm{K}$-dosed surface.

If we accept the proposal of Crowell et al. [4] for the results of isotopic exchange between ${ }^{13} \mathrm{C}^{16} \mathrm{O}$ and ${ }^{12} \mathrm{C}^{18} \mathrm{O}$ in the presence of $\mathrm{K}$ adatoms, namely that the dissociation, scrambling, recombination and desorption all occur as a concerted process, then it follows that the $\mathrm{CO}$ formed in the recombination of surface $\mathrm{C}$ and $\mathrm{O}$ at $400-500 \mathrm{~K}$ would dissociate and recombine again around $640-700 \mathrm{~K}$, which is highly unlikely. Therefore we incline to think that the isotopic scrambling for adsorbed $C O$ on $K / R h(111)$ is the result of an exchange reaction in a molecular surface complex and not due to the dissociation and immidiate subsequent scrambling of surface $C$ and $O$.

\section{Conclusions}

(1) The major characteristics of the effect of potassium on $\mathrm{CO}$ adsorption on $\mathrm{Rh}$ (111) agree well with those observed for other Pt metals.

(2) UPS and XPS data provide no evidence for the K-induced dissociation of $C O$ in the range of $\mathrm{K}$ coverage $\theta_{\mathrm{K}}=0.05-0.33$ (up to $604 \mathrm{~K}$ ), just below the temperature of $\mathrm{CO}$ desorption.

(3) It appears that potassium greatly promotes the recombination of adsorbed oxygen and carbon (produced by electron bombardment or by decomposition of ethylene); the formation of chemisorbed $\mathrm{CO}$ at $\theta_{\mathrm{K}}=0.33$ was observed at $400-500 \mathrm{~K}$.

(4) It is suggested that the isotopic scrambling between labelled CO previously observed before on $\mathrm{K}$-dosed $\mathrm{Rh}(111)$ [4] occurs by a molecular exchange mechanism and does not involve significant dissociation of $\mathrm{CO}$ to carbon and oxygen.

\section{References}

[1] F. Solymosi and L. Bugyi, J. Chem. Soc. Faraday Trans. I, 83 (1987) 2015.

[2] J. Kiss, K. Revesz and F. Solymosi, Surface Sci. 207 (1988) 36.

[3] J.E. Crowell and G. Somorjai, Appl. Surface Sci. 19 (1984) 73.

[4] J.E. Crowell, W.T. Tysoe and G. Somorjai, J. Phys, Chem. 89 (1985) 1598.

[5] B.A. Sexton and G. Somorjai, J. Catalysis 46 (1977) 167.

[6] D.G. Castner and G. Somorjai, Surface Sci. 83 (1979) 60. 
[7] P.A. Thiel, E.D. Williams, J.T. Yates, Jr. and W.H. Weinberg, Surface Sci. 91 (1979) 54.

[8] J.T. Yates, Jr, E.D. Williams and W.H. Weinberg, Surface Sci. 91 (1981) 562.

[9] D.G. Castner, L.H. Dubois, B.A. Sexton and G. Somorjai, Surface Sci. 103 (1981) 134.

[10] V.V. Gorodetskii and B.E. Nieuwenhuys, Surface Sci. 105 (1981) 299.

[11] M. Primet, Trans. Faraday Soc. I, 74 (1978) 2570.

[12] F. Solymosi and A. Erdohelyi, Surface Sci. 110 (1981) L630.

[13] A. Erdöhelyi and F. Solymosi, J. Catalysis 84 (1983) 446.

[14] G. Broden, T.N. Rhodin, C. Brucker, R. Bendow and Z. Hurych, Surface Sci. 59 (1976) 593.

[15] F. Solymosi and A. Berko, Surface Sci 201 (1988) 361.

[16] G. Broden, G. Gafner and H. Bonzel, Surface Sci. 84 (1979) 295;

J. Benzinger and R.J. Madix, Surface Sci. 94 (1980) 119;

U. Seip, I.C. Bassignana, J. Küppers and G. Ertl, Surface Sci. 160 (1985) 400;

S.D. Cameron and D.J. Dwyer, Surface Sci. 198 (1988) 315.

[17] M.P. Kiskinova, Surface Sci. 111 (1981) 584.

[18] H.S. Luftman, Y.M. Sun and J.M. White, surface Sci. 141 (1984) 82; Appl. Surface Sci. 19 (1984) 59.

[19] L. Ng, K.J. Uram, Z. Xu, P.L. Jones and J.T. Yates, Jr., J. Chem. Phys. 86 (1987) 6523.

[20] J. Lee, J. Arias, C.P. Hanrahan, R.M. Martin and H. Metiu, Phys. Rev. Letters 51 (1983) 1991.

[21] L.J. Whitman and W. Ho, J. Chem. Phys. 83 (1985) 4808.

[22] R.A. dePaola, J. Hrbek and F.M. Hoffmann, J. Chem. Phys. 82 (1985) 2484.

[23] J.J. Weimer, E. Umbach and D. Menzel, Surface Sci. 155 (1985) 132.

[24] F.P. Netzer, D.L. Doering and T.E. Madey, Surface Sci. 143 (1984) 1363;

T.E. Madey and C. Benndorf, Surface Sci. 164 (1985) 602.

[25] J.C. Bertolini, P. Delichere and J. Massardier, Surface Sci. 160 (1985) 531.

[26] J.E. Crowell, E. Garfunkel and G.A. Somorjai, Surface Sci. 121 (1982) 303.

[27] M. Kiskinova, G. Pirug and H.P. Bonzel, Surface Sci. 133 (1983) 321.

[28] A. Berko and F. Solymosi, Surface Sci. 171 (1986) L498.

[29] D. Lackey and D.A. King, J. Chem. Soc. Faraday I, 83 (1987) 2001.

[30] A. Berko and F. Solymosi, J. Chem. Phys. 90 (1989) 2492.

[31] R.M. Lambert and C.M. Comrie, Surface Sci. 38 (1973) 197.

[32] W. Wurth, J.J. Weimer, E. Hudeczek and E. Umbach, Surface Sci. 173 (1986) L619.

[33] A.J. Slavin, B.E. Bent, C.-T. Kao and G.A. Somorjai, Surface Sci. 206 (1988) 124.

[34] H.P. Bonzel, Surface Sci. Rept. 8 (1988) 43.

[35] D.E. Pebbles, H.C. Peebles and J.M. White, Surface Sci. 136 (1984) 463.

[36] K.C. Prince and A.M. Bradshaw, Surface Sci. 126 (1983) 49.

[37] J.J. Weimer, W. Wurth, E. Hudeczek and E. Umbach, J. Vacuum Sci. Technol. A 4 (3) (1986) 1347.

[38] D. Heskett, E.W. Plummer, R.A. dePaola and W. Eberhardt, Phys. Rev. B 33 (1986) 5171.

[39] D. Heskett, Surface Sci. 199 (1988) 67.

[40] J. Hrbek, R. De Paola and F.M. Hoffmann, Surface Sci. 166 (1986) 361; 169 (1986) L348.

[41] A. Berko, T.1. Tarnoczi and F. Solymosi, Surface Sci. 189/190 (1987) 238; J. Chem. Phys. 87 (1987) 6745.

[42] F. Solymosi, J. Kiss and I. Kovacs, J. Phys. Chem. 92 (1988) 796.

[43] A. Berko and F. Solymosi, J. Phys. Chem. 93 (1989) 12.

[44] A. Berko and F. Solymosi, Surface Sci. 171 (1986) L498.

[45] F. Solymosi and A. Berko, J. Catalysis 101 (1986) 458.

[46] Z.M. Liu, Y. Zhou, F. Solymosi and J.M. White, J. Phys. Chem. 93 (1989) 4383.

[47] D. Lackey, M. Surman, S. Jacobs, D. Grider and D.A. King, Surface Sci. 152/153 (1985) 513.

[48] F. Solymosi an L. Bugyi, Surface Sci. 210 (1988) L193.

[49] P.M. Blass, B. Roop, X.L. Zhou and J.M. White, J. Chem. Phys. 90 (1989) 608. 
[50] H.J. Jänsch, C. Huang, A. Ludviksson, J. Redding, H. Metiu and R.M. Martin, Surface Sci. 222 (1989) 199.

[51] A. Bossi, G. Carnision, F. Garbassi, G. Giunchi, G. Petrini and L. Zanderighi, J. Catalysis 65 (1980) 16.

[52] D. Panayotov, P. Basu and J.T. Yates, Jr., J. Phys. Chem. 92 (1988) 6066.

[53] S.D. Jackson, J. Catalysis 108 (1987) 250.

[54] J. Arias, J. Lee, J. Dunaway, R.M. Martin and H. Methiu, Surface Sci. 159 (1985) L433;

J. Lee, J. Arias, C.R. Hanrahan, R.M. Martin and H. Metiu, J. Chem. Phys. 82 (1985) 485.

[55] T. Matsushima, Z. Phys. Chem. (NF) 158 (1988) 175. 